\title{
J
}

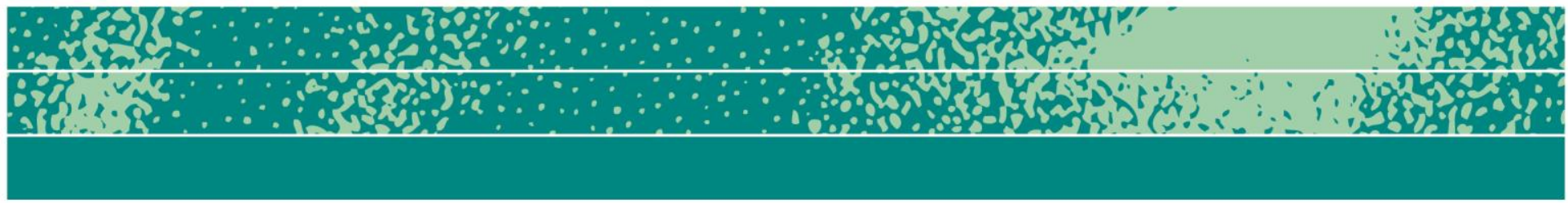

Editors' Letter

\section{Creative Engagements and Cross-Disciplinary Approaches to the Study of Business}

\author{
Brian Moeran and Dixon Heung-wah Wong
}

For this autumn issue of the Journal of Business Anthropology, we decided as co-editors that we wanted to push business anthropology sideways, and hopefully forward, by bringing it face to face with some of those other disciplines-mainly housed in business schools-which in their different ways study business organizations and relations of one sort or another. This was the thinking behind (Creative Engagements, a small intensive workshop that we organized at the University of Hong Kong in April this

Page 1 of 4

JBA 3(2): 136-139 Fall 2014

(C) The Author(s) 2014 ISSN 2245-4217

www.cbs.dk/jba year. The discussions among workshop participants have led to most of the article-essays published in this issue of the JBA.

The workshop announcement framed things in the following way. The study of business organizations and relations is fraught with all kinds of challenges. Some of these stem from the object of academics' research and concern issues of access, confidentiality, communication of results, and so on. Others are to be found in researchers' own theoretical attitudes and methodological practices. These often reinforce disciplinary boundaries and so preclude the cross-fertilization of ideas-a crossfertilization that, in theory at least, is supposed to be the hallmark of intellectual engagement and enrichens researchers' ways of thinking.

Creative Engagements brought together two sets of people with common intellectual aims, but somewhat disparate practices, in an attempt to bridge disciplinary gaps between social and cultural 
anthropology, on the one hand, and what may be broadly termed management and business studies (including finance, marketing, organization studies, and so on), on the other. Its aim was to provide scholars in different fields with an opportunity to reflect upon the strengths and weaknesses of their own disciplinary approaches, and to learn from and engage with other disciplines focusing on the study of business.

About a dozen participants were therefore invited to prepare critical reflective papers on their own particular field of research, to point to its strengths, weaknesses, and potential future strands of development. Questions that they were asked to bear in mind included: What is so good about the ways in which I carry out my research? How might I improve them? What can I learn from those in other disciplines studying the same field of business? Do disciplinary boundaries help or hinder the furtherance of ideas? Is it wise to transgress them? If so, how best might we do so?

During the two-day workshop at The University of Hong Kong in April 2014, we paired one anthropologist with one "management scientist" (representing such diverse fields of scholarship as crosscultural management, marketing, organization studies, economics, and law) to make brief presentations on a common topic from their different disciplinary viewpoints: research methods, culture, discourse, and so on. This was followed by open discussion among all participants. At the end of the workshop, each pair of anthropologist and management scientist was invited to collaborate on a joint paper converting this dialogue into written text, and to submit the result to the Journal of Business Anthropology for publication in this issue. Not everyone present was able to submit their collaborative papers in time (we anticipate publication of at least one more collaboration in next spring's issue of the $J B A$ ), but we still were able to gather some interesting essays and these are published here.

Creative Engagements was designed, first and foremost, to propel business anthropology out of its potential siloization by asking its practitioners to engage with other scholars who may have some inkling of what anthropology is, but who certainly are not aware of its full potential, and who can as a result be somewhat suspicious of anthropologists lurking in their midst-as Alex Stewart reminds us from his personal experiences of employment in business school environments. In business corporations, too, the same attitude can prevail until a fortuitous development-the sudden awareness that corporations, and not just nations, might also have "culture," for example-can propel a resident anthropologist into the limelight. As Allen Batteau wrily remarks, sometimes you get lucky-especially if you stay around long enough!

Anthropology was traditionally the study of "mankind," and mankind, as David Westbrook points out, was quickly conflated, first, with 
"culture" and then, because anthropologists went off to do fieldwork in exotic places, with "other cultures." Fieldwork and culture have, as a result, dominated other disciplines' understandings of anthropology. Scholars in "business studies" (broadly construed) limit themselves to references to Clifford Geertz's "thick description" when talking about their understandings of "ethnography." They blithely-and, until recently, uncritically, as Nigel Holden explains in a critique of his own discipline's practices-endorse Geert Hofstede's theory of "cultural dimensions" when discussing cross-cultural management. This can lead to a collective groan on the part of anthropologists who-as we have had had occasion to remark elsewhere in the pages of this journal-do more than fieldwork for their living, and who focus on more than culture (however that may be defined) in their analyses of what they study.

We felt it was our task, therefore, to lead those in business and management studies out of their own intellectual ghettoes by showing them that anthropology can be more than a vague and often overgeneralized notion of "culture." How could we achieve this? By making them aware of ways in which anthropological theories of magic, for example, developed in the context of explaining "irrational" behaviour in "primitive" societies, might usefully and profitably be applied to the analysis of contemporary business formations such as advertising, and other forms of cultural production; ${ }^{1}$ by showing how classical anthropological notions of liminality, ritual, social drama, purity and pollution-as well as forms of sociality, networks, money, value and values discussed by Batteau-might provide colleagues in other disciplines with food for intellectual analysis.

At the same time, we were convinced that the learning process must be two-way-a conviction that has only been strengthened by the difficulties we have encountered along the way to editing this issue of the $J B A$. Business anthropology has much to learn from neighbouring disciplines when it comes to the study of business organizations and relations. OK, we can laugh at cross-cultural management scholars' indiscriminate usage of Geert Hofstede ("Geertz who?" As an anthropologist colleague once asked). But, as a group of like-minded scholars who believe in the principle of participant-observation and intensive fieldwork in business organizations, and therefore in what people say they do, we would do well to pay more attention, for instance, to theories of discourse developed outside our own narrow field-as Dan Kärreman and Elizabeth Briody so eloquently and engagingly demonstrate. Other areas that anthropologists might do well to learn from include organization studies, marketing, and international business.

Needless to say, perhaps, inter-disciplinary engagements of this kind are more easily talked about than achieved in our contemporary

\footnotetext{
${ }^{1}$ See Brian Moeran (2014) “Business, anthropology, and magical systems.” 2014 EPIC Conference Proceedings.
} 
academic world. It may be that, as a "weak" discipline, it is easier for anthropology to step out of the confines of its discipline. As Westbrook points out, anthropology, like law, may not even meet received notions of what constitutes an academic discipline (at least, when compared with a subject like mathematics). Every academic discipline can be seen as a paradigm-in the sense of referring to "the idea of community consensus and its acceptance" 2 -which is itself usually divided into many different sub-paradigms within that discipline (and law, with its numerous "and " variations is a good example of this). In other words, disciplinary divides are a matter of boundary maintenance, which is not necessarily related to the scientific nature of a certain discipline, but to its politics.

Now, so far as we ourselves are concerned, academic politics isn't a problem because politics exists in all human collectivities. The most serious problem is that practitioners mistakenly take academic politics as a matter of scientific truth or falsity. Some-if not the majority of anthropologists of business - tend to reject the studies of business by management scholars on such putative grounds as the claim that management science is a pseudo-science (in which case, what on earth is anthropology?), while many management scientists ignore a lot of the work done by business anthropologists because it tends not to be reducible to quadripartite models or bullet points. As a result, neither side reads the other's work, and rarely-if ever-engages in serious dialogue. We believe that anthropologists of business should talk to management scientists and vice versa because the concept of a disciplinary boundary is a contemporary product of the Enlightenment, and thus arbitrary and historical. It can and should be transgressed.

The first step into such transgression is to learn and find out what business anthropologists and management scientists are doing, what the ontological bases on which their disciplinary pursuits are conducted look like, and what methodological and theoretical criteria underpin how consensus and acceptance are established in each of these two disciplines. We believe the time is ripe for such creative engagements, even though we have encountered resistance on both sides of the disciplinary fence. We intend, therefore, to pursue such cross-disciplinary perspectives in future issues of the $J B A$, and to broaden the study of business anthropology to the study of business as a whole. Hopefully, we will in the process reclaim some of the acres of intellectual space lost by anthropologists who in the past refused to take business seriously as a legitimate subject of scholarship.

2 Bernard S. Cohn (1980) "History and anthropology: the state of play." Comparative Studies in Society and Culture, 22 (2): 198-221. 